\title{
THE NUMBER OF IMMUNOREGULATORY T CELLS IS INCREASED IN PATIENTS WITH PSORIASIS AFTER GOECKERMAN THERAPY
}

\author{
Kateřina Kondělková1, Doris Vokurková1, Jan Krejsek', Lenka Borská2 ,Zdeněk Fialaª , Květa Hamákovát, \\ Ctirad Andrýs ${ }^{1}$
}

Charles University in Prague, Faculty of Medicine and University Hospital Hradec Králové, Czech Republic: Department of Clinical Immunology and Allergology ${ }^{1}$, Department of Pathological Physiology ${ }^{2}$, Department of Hygiene and Preventive Medicine ${ }^{3}$, Department of Dermatology and Venerology ${ }^{4}$

\begin{abstract}
Summary: Regulatory T cells (Treg) are a specialized subpopulation of T cells that act to suppress inadequate immune response. Psoriasis is recognized as a T-cell driven immune-mediated systemic inflammatory disease with skin manifestation. Effective therapeutical approach to treat psoriasis is Goeckerman therapy (GT). The aim of this study was to compare the number of Treg in the peripheral blood of 27 psoriatic patients and 19 controls and to evaluate the influence of GT on Treg population in peripheral blood of patients with psoriasis. There was no significant difference in the relative number of Treg cells in the peripheral blood of healthy blood donors and patients with psoriasis before initiation of GT (P=0.2668). In contrary, the relative number of Treg cells in peripheral blood of patients with psoriasis after GT was significantly higher than those found in healthy blood donors $(\mathrm{P}=0.0019)$. Moreover, the relative number of Treg is significantly increased in psoriatic patients after Goeckerman therapy compared to the pre-treatment level $(\mathrm{P}=0.0042)$. In conclusion, this significant increase in Treg count after GT is probably associated with amelioration of inflammation by GT, as disease activity expressed as PASI decreased in our patients by GT $(\mathrm{P}=0.0001)$.
\end{abstract}

Key worlds: Regulatory T cells; Psoriasis; Goeckerman therapy

\section{Introduction}

Regulatory $\mathrm{T}$ cells (Treg) are characterized as a functionally highly specialized $\mathrm{T}$ cell subset responsible for optimal control of the immune response. Several subsets of Treg cells have already been identified, such as natural CD4+ Treg cells, Th3 cells, Tr1 cells, and CD8+ Treg cells. It is very likely that the other distinct subsets will be added to this list in future. Natural Treg cells represent $5-10 \%$ of total CD4+ helper inducer T cells. They are characterized by the intermediate to high expression of the cell surface $\alpha$-subunit of IL-2 receptor (CD25), as well as the intracellular expression of transcription factor FoxP3. Phenotype of Tr1 cells is CD25-FoxP3-CD4 ${ }^{-}$. These cells, upon activation via the TcR, produce high amounts of IL-10 and very low levels of IL-2 but they do not produce IL-4 (7). Th3 cells are phenotypically resembling $\operatorname{Tr} 1$ cells but their principal modulator is TGF- $\beta$. CD $8+$ Treg cells are $\mathrm{CD} 25^{+} \mathrm{FoxP} 3^{+}$and they play an important role in a protective immunity $(3,16,36)$. Treg cells reveal suppressive function via a mechanism that requires cell to cell contact (natural CD4+ Treg cells) or the secretion of anti-inflammatory cytokines (adaptive Treg cells) $(5,17,33)$. Another mechanism of Treg cells action is their cytotoxic activity which is mediated by granzymes and perforin release. Numerous target cells including both $\mathrm{CD} 4+$ and $\mathrm{CD} 8+$ subpopulations of T cells $(11,13)$, NK, and NKT cells, monocytes, dendritic cells, and granulocytes are regulated by this cytotoxic activity of Treg cells $(26,32,34)$. Treg are able to restrict CD8+ memory effector $\mathrm{T}$ cells $(20,26)$. Thus, it is conceivable that increased number of cutaneous Treg cells could diminish pathogenic inflammatory CD8 $+\mathrm{T}$ cell functions in the psoriasis (23).

It is widely accepted that psoriasis is a systemic, predominantly $\mathrm{T}$ cell-mediated inflammatory disorder with skin manifestation. It affects approximately $2 \%$ of the world's population. This disease is characterized by hyperproliferation and abnormal differentiation of keratinocytes with activated $\mathrm{T}$ cells and granulocytes accumulated in involved skin areas. Psoriasis is a multifactorial disease in which both genetic predisposition and many variable incipiting factors such as infection, stress, skin trauma, to list only some, are involved $(2,31)$. Psoriatic Treg cells are functionally deficient in suppressing effector $\mathrm{T}$ cell responses. Although this deficiency is not absolute, higher numbers of psoriatic Treg cells are required to provide suppression similar to that of normal regulatory cells (31). These findings suggest that Treg cells are involved in the pathogenesis of psoriasis $(23,29,31)$. Defects in the function or count of Treg appear to be common in different autoimmune diseases (10). 
Goeckerman therapy (GT) is based on daily skin application of pharmaceutical coal tar with subsequent body exposition to UV light. This therapeutic approach is still preferred for its simple application, good clinical response, and low cost $(12,22)$. There are very sparse information addressing the influence of GT therapy of psoriasis on Treg cells. Therefore we aimed our research on this topic. Here we present our results which, to the best of our knowledge, for the first time confirmed that the relative count of $\mathrm{CD}^{+} /$ $\mathrm{CD}^{+} / \mathrm{CD} 25^{+} / \mathrm{CD} 127^{\text {low } /-}$ Treg is increased after Goeckerman therapy of psoriasis.

\section{Materials and Methods}

\section{Study group}

The study was approved by the Ethics Committee of the University Hospital in Hradec Králové. Informed written consent was obtained from each patient. 27 adult patients with psoriasis were enrolled to this study. Our study group consisted of 16 females and 11 males (average age: $44.5 \pm$ 22.7 years). Patients with psoriatic arthritis were excluded from the study. 19 otherwise healthy blood donors (6 females, 13 males, average age: $38.9 \pm 10.9$ years) served as a control group.

\section{Goeckerman therapy}

Goeckerman therapy was indicated by the consulting dermatologist with patient-to-patient adjustments based on the activity of disease. The average duration of therapy was 15 days. The efficacy of Goeckerman therapy was assessed by clinical evaluation of erythema, desquamation, and skin infiltration using PASI score (Psoriasis Area Severity Index). The PASI score was calculated before and after treatment for each patient. GT is ceased when 30\% decrease of PASI is achieved. Coal tar ointment with 5\% pharmaceutical grade coal tar was applied daily overnight on affected skin (10-75\% of total body surface). Each morning, the excess tar ointment was removed with oil bath. After the tar removal, the patient was irradiated with UV light. The duration of UV irradiation was individual, depending on disease activity (range $1-15$ minutes). The light beam density (dose) was controlled by Sola-Scope 2000 spectrometer (Solatell, UK) and was $245.60 \mu \mathrm{W} / \mathrm{cm}^{2}$ for UV-B radiation and $134.4 \mu \mathrm{W} / \mathrm{cm}^{2}$ for $\mathrm{UV}-\mathrm{A}$ radiation. Previous exposure of patients to UV irradiation and polyaromatic hydrocarbons was assessed by a questionnaire. Patients with this positive personal history were excluded from the study. Samples of heparinized venous blood were obtained by venipuncture of the cubital vein before treatment and again after completion of Goeckerman therapy (at the day of dismissal from the hospital) using BD Vacutainer sampling tubes. Venous blood was also collected from otherwise healthy blood donors who served as control.

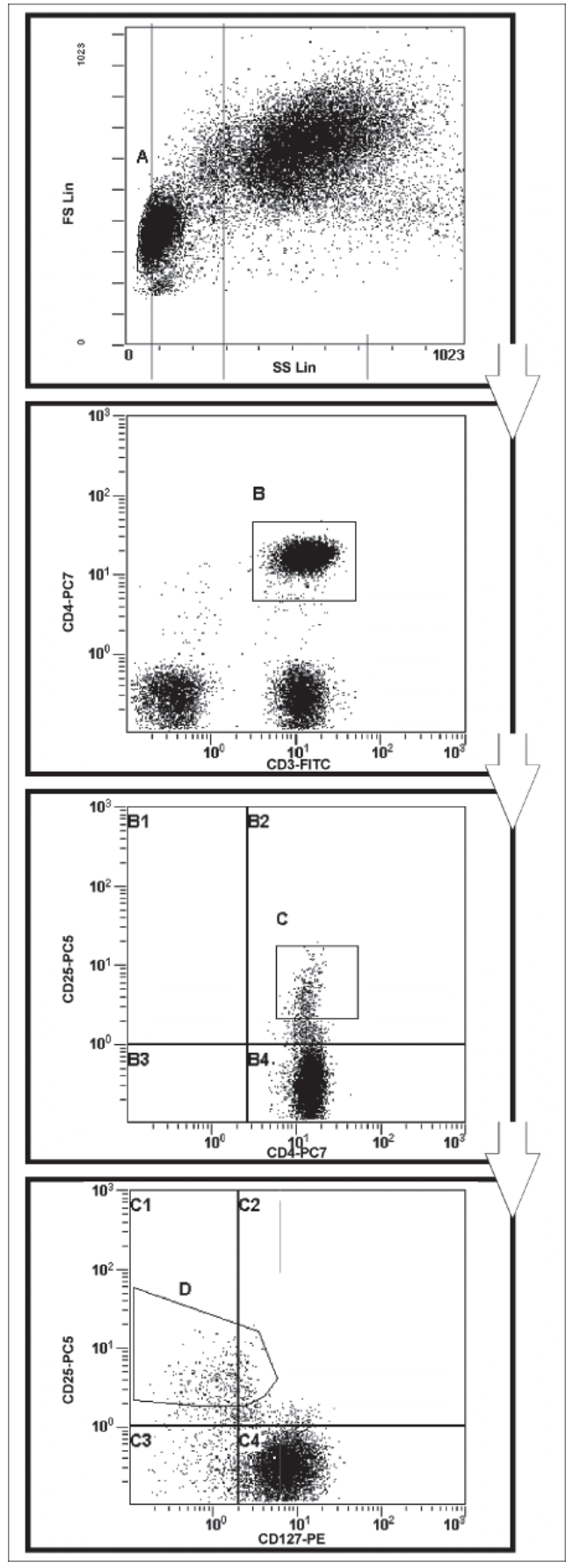

Fig. 1: Gating strategy to identify Treg cells. Peripheral blood obtained from healthy volunteers or psoriatic patients was stained with antibodies against CD3, CD127, CD25 and CD4. Lymphocyte population was gated by using SS (side scatter) and FS (forward scatter) dot plot (gate A). Then we used CD3 and CD4 antibodies to select $\mathrm{CD}^{+}{ }^{+} \mathrm{CD} 4{ }^{+}$population (gate B). By using CD25 antibody we gated $\mathrm{CD} 3^{+} \mathrm{CD} 4^{+} \mathrm{CD} 25^{\text {high }}$ positive cells (gate $\mathrm{C}$ ). Then we used antibody CD127 and defined final population of $\mathrm{CD} 3{ }^{+} \mathrm{CD} 4{ }^{+} \mathrm{CD} 25^{\text {high }} \mathrm{CD} 127^{\text {low } /-}$ - Treg cells (gate D). 


\section{Flow cytometry}

The method which is now readily available to identify Treg cells is flow cytometry. However it is a difficult task to identify Treg cells by flow cytometry, as the most specific marker FoxP3 which is localized intracellulary is only detectable after cell permeabilization $(7,8,30)$. Permeabilization step is laborious and confounding results are sometimes found. Therefore, it has been recently recognized that FoxP3+ cells are expressing CD127 in a significantly lower density. CD127 is a subunit of IL$7 \mathrm{R}(15)$. It was proved experimentally that $\mathrm{CD}^{+} / \mathrm{CD}^{+} /$ CD25 high/CD127low/- cells are FoxP3+. It is now generally accepted that this phenotype can serve as a surrogate marker for Treg cells $(24,35)$. For routine testing, CD25 high/ CD127low/- phenotype is enough specific and sensitive to identify Treg cells.

The immunophenotypic analysis was performed on erythrocyte lysed peripheral blood using a flow cytometer FC500 Cytomics (Beckman Coulter) with a 4-color antibody panel (Immunotech): CD3-FITC/CD127-PE/CD25-PC5/ CD4-PC7. Appropriate isotype-matched negative control was used to avoid the influence of the background fluorescence staining. The obtained data were analysed using software CXP Analysis. Treg were characterized by the expression of $\mathrm{CD} 3{ }^{+} \mathrm{CD} 4{ }^{+} \mathrm{CD} 25^{\text {high }} \mathrm{CD} 127^{\text {low }}{ }^{-}$phenotype (Fig. 1). Treg counts are expressed as percentage of CD4+ T lymphocyte subpopulation in peripheral blood. Cytometric analyses were run by $\mathrm{K}$. K. and $\mathrm{D}$. V. who were blind to patient's status to eliminate bias.

\section{Statistical analysis}

Statistical differences between the groups were evaluated by non-paired and paired t-test (MedCalc software, Belgium) after data normality evaluation. To exclude confounding effect of different age and sex presentation in patients and controls, unpaired t-test and chi-square was performed. The results are given as the mean \pm standard deviation. $\mathrm{P}$ value less than 0.05 was considered as significant.

\section{Results}

Disease activity was significantly positively affected by Goeckerman therapy. Good clinical response was achieved in all patients. Pre-therapy PASI score $17.5 \pm 6.5$ dropped to $8.4 \pm 4.6$ after therapy $(\mathrm{P}<0.0001)$.

At first, we compared Treg levels in normal and psoriatic blood. There was no significant difference in the number of Treg cells in the peripheral blood of healthy blood donors $(2.9 \pm 1.0 \%)$ and patients with psoriasis before initiation of GT $(3.3 \pm 1.2 \%) ; \mathrm{P}=0.2668$. Compared to controls $(2.9 \pm 1.0 \%)$ the relative number of Treg cells in peripheral blood of patients with psoriasis after GT $(4.3 \pm 1.6 \%)$ was significantly elevated $(\mathrm{P}=$ $0.0019)$. The relative number of Treg was significantly higher in the patients with psoriasis after GT $(4.3 \pm$ $1.6 \%)$ than at the beginning of the therapy $(3.3 \pm 1.2 \%)$; $\mathrm{P}=0.0042$ (Fig. 2). Our results are summarized in Fig. 3.

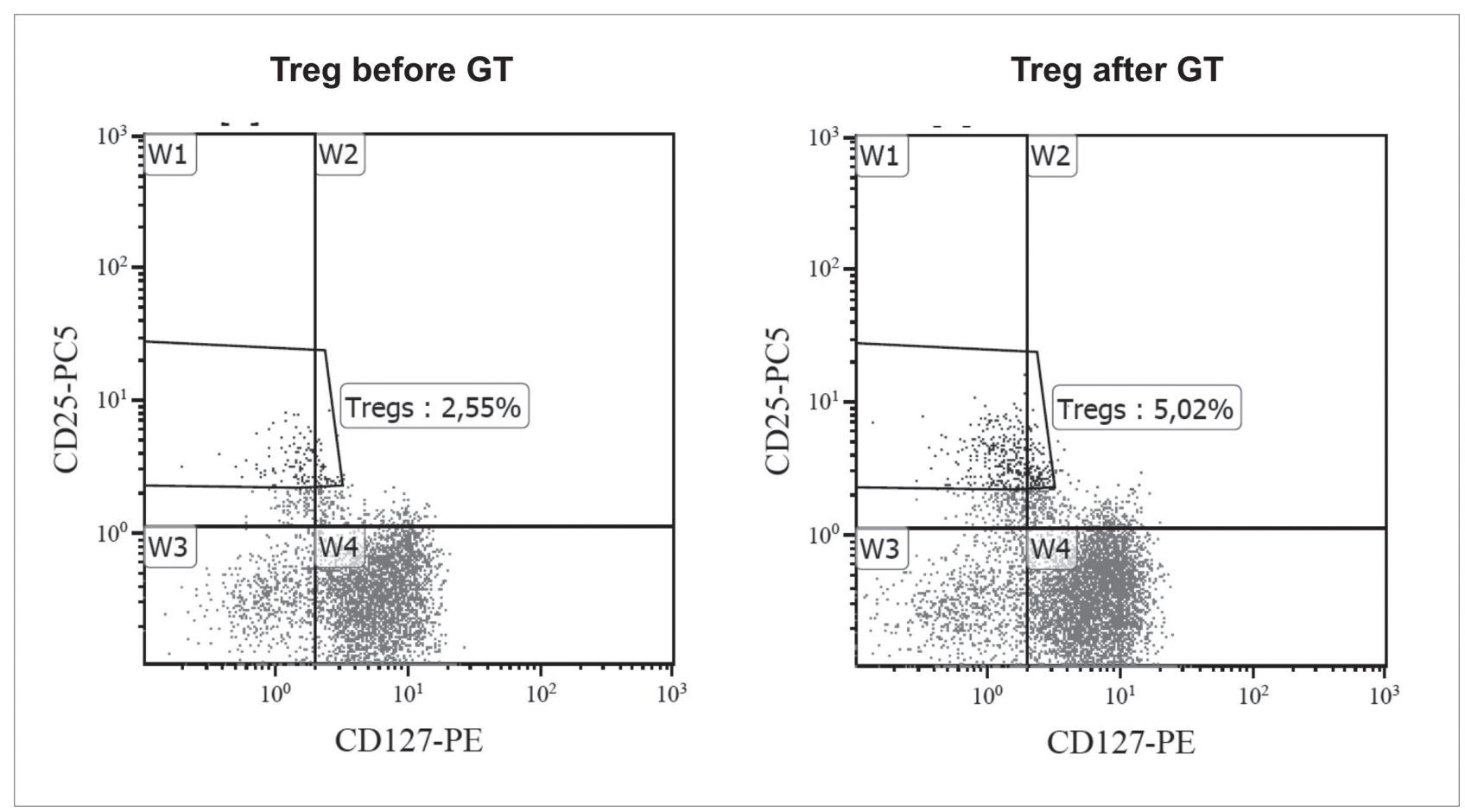

Fig. 2: Relative number of Treg cells in peripheral blood of one patient with psoriasis before and after Goeckerman therapy 


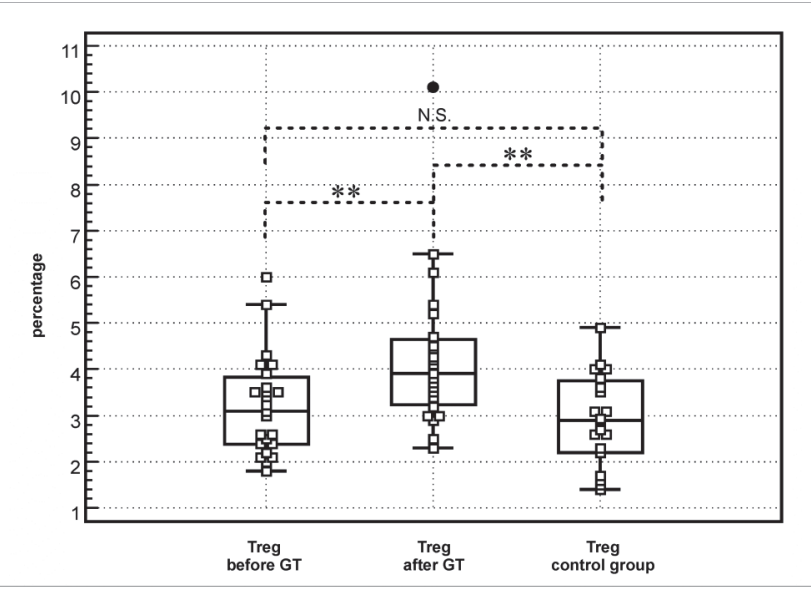

Fig. 3: Percentages of Treg cells in healthy blood donors and patients with psoriasis before and after GT.

\section{Discussion}

It is known that psoriasis is a disease with multifactorial origin, and in combination with other critical factors (e.g. genetic predisposition), defects in Treg cell function may contribute to overall disease pathogenesis $(29,31)$.

Regulatory $\mathrm{T}$ cells are a specialized, phenotypically, and functionally distinct subpopulation of T cells that modulate immune response, thereby maintaining homeostasis and self-tolerance $(17,37)$. Defect in a distinct Treg subset results in enhanced inflammatory reaction directed predominantly to the mucosal surfaces. Treg are a good target for investigation of immunopathogenesis, diagnoses, treatment and, or prevention of immunological disorders.

Skin is normally covered with innocuous and weakly immunogenic normal microbial flora, to which vigorous ongoing immune responses would cause immunological chaos and chronic inflammation. Treg limit effector $\mathrm{T}$ cell activation to this normal nonpathogenic resident flora, while permitting the necessary $\mathrm{T}$ cell activation to acute infection $(14,18)$. Bovenschen et al. reported that whereas $\mathrm{CD} 4{ }^{+} \mathrm{CD} 25^{+} \mathrm{FoxP}^{+}$Treg cells were completely absent in normal skin biopsies, these cells were both found in the upper psoriatic dermis and to a minimal extent in the epidermis of psoriatic skin. They indicated that Treg cells are not able to exert their local suppressive function on pathogenic $\mathrm{T}$ cells in the dermis and the epidermis of patients with psoriasis (5).

The ability to induce Treg cells and to promote their long-term survival in the periphery could be the proof of efficacy of immunosuppressive therapy. These induced Treg are capable of inhibiting proliferation of effector $\mathrm{T}$ cells $(1,21,39)$. Up-regulation of Treg cell function or increase in the number of these cells might be beneficial for treatment of autoimmune diseases and allergies, and to prevent allograft rejection. Moreover, inhibiting Treg cell function or decreasing Treg number might dampen immunity against tumors and pathogenic microorganisms (25).
Chen et al. emphasized that the balance between activated effector cells and Treg cells is important for efficient immune response (6). In psoriasis, the imbalance between Treg and effector $\mathrm{T}$ cells has been recently described by several groups. Their findings suggest that the number and/ or function of Treg cells may be impaired with consequent hyperproliferation of pathogenic $\mathrm{T}$ cell in psoriasis $(6,31$, $38)$. In accordance with other reports $(6,29,31,38)$, we found that Treg frequency in peripheral blood of psoriasis patients is comparable to that of healthy controls. Saito et al. reported that the percentage of $\mathrm{CD} 4^{+} \mathrm{CD} 25^{+} \mathrm{FoxP} 3^{+}$Treg in peripheral blood mononuclear cells isolated from patients with psoriasis before bath-PUVA therapy was slightly lower than that in cells from healthy volunteer, but the difference was not significant (29). In line with our results, the percentage of Treg cells in the psoriatic patients was significantly higher after bath-PUVA therapy. Chen et al. as well as Zhang et al. reported that there is no significant difference in Treg cells in patients with psoriasis compared with normal controls $(6,38)$. Sugiyama et al. found that Treg in psoriatic patients displayed impaired suppressor activities that are not associated with a decrease in their number in the peripheral blood. They proposed that this impairment of Treg cells can ultimate to the failure of regulation of autoreactive $T$ cells with their subsequent overproliferation in patients with psoriasis (31). Quaglino et al. demonstrated that therapy with biological drugs (infliximab, etanercept, efalizumab) is able to up-regulate the expression of the CD4+CD25 brightFoxP3+ Treg cell subset and that this increase is associated with the achievement of a clinical response (27). Furuhashi et al. reported that levels of Treg cells in patients with palmoplantar pustulosis after excimer light therapy $(308 \mathrm{~nm})$ were significantly higher than those at baseline (9).

This study in which we showed that the number of Treg cells in peripheral blood of patients with psoriasis is increased after Goeckerman therapy, adds a substantial supplementary piece to the list of GT immunomodulatory effects. Despite the long-time history of GT its immunomodulatory mechanisms are still not known in details. The most important drawback of this therapy is entire lack of knowledge of coal tar composition. Coal tar consists of largely undefined aliphatic and aromatic hydrocarbons which in combination with immunomodulatory effect of UV irradiation are responsible for diminished hyperproliferation of epidermal cells $(12,22)$. The combination of coal tar and UV light has been reported to be more effective than either therapy alone (19). Coal tar displays anti-inflammatory, antibacterial and antipruritic effects. It reveals also a photodynamic effect that makes the skin more sensitive to UV light (28). UV exposure induces the local and systemic suppression of the inflammatory response. It induces $T$ cells with suppressor activity, inhibits the function of antigen-presenting cells, and stimulates the release of immunosuppressive cytokines (4).

Data addressing the influence of Goeckerman therapy on the number of $\mathrm{T}$ regulatory cells in patients with 
psoriasis are entirely lacking. Our study is the first attempt to study effects of GT on Treg cells.

\section{Conclusion}

In conclusion, we found that the number of Treg cells is significantly increased in patients with psoriasis after Goeckerman therapy. With regard to our results we propose that the number and/or function of Treg cells may be involved in the pathogenesis of psoriasis. The elevation of these cells after GT could be explained by the anti-inflammatory action of GT therapy. We hypothesize that Treg cells induced by GT might be functional and may contribute to the achievement of a good clinical response followed by long-term remission. Assessment of Treg cells may by useful marker of beneficial effects of Goeckerman therapy in patients with psoriasis.

\section{Acknowledgements}

This study was supported by Research project, Ministry of Health, Czech Republic, No. 00179906, Ministry of Education, Czech Republic, project No. MSM0021620812 and by the programme PRVOUK P37/09.

We thank Mrs. Hana Kotlandova for her graphic assistance.

\section{References}

1. Battaglia M, Gregori S, Bacchetta R, Roncarolo M-G. Tr1 cells: from discovery to their clinical application. Semin Immunol 2006; 18(2): 120-7.

2. Bevelacqua V, Libra M, Mazzarino MC et al. Long pentraxin 3: a marker of inflammation in untreated psoriatic patients. Int J Mol Med 2006; 18: 415-23.

3. Bisikirska B, Colgan J, Luban J, Bluestone JA, Herold KC. TCR stimulation with modified anti-CD3 mAb expands CD8+ T cell population and induces CD8+CD25+ Tregs. J Clin Invest 2005; 115(10): 2904-13.

4. Borska L, Andrys C, Krejsek J et al. Genotoxic and apoptotic effects of Goeckerman therapy for psoriasis. Int J Dermatol 2010; 49: 289-94.

5. Bovenschen HJ, van Vlijmen-Willems IM, van de Kerkhof PC, van Erp PE. Identification of lesional CD4+ CD25+ Foxp3+ regulatory T cells in Psoriasis Dermatology 2006; 213(2): 111-7.

6. Chen L, Shen Z, Wang G, Fan P, Liu Y. Dynamic frequency of CD4+CD25+Foxp3+ Treg cells in Psoriasis vulgaris. J Dermatol Sci 2008; 51(3): 200-3.

7. Fontenot JD, Rasmussen JP, Williams LM, Dooley JL, Farr AG, Rudensky AY Regulatory $\mathrm{T}$ cell lineage specification by the forkhead transcription factor foxp3. Immunity 2005; 22(3): 329-41.

8. Fontenot JD, Rudensky A. A well adapted regulatory contrivance: regulatory T cell development and the forkhead family transcription factor Foxp3. Nat Immunol 2005; 6(4): 331-7.

9. Furuhashi T, Torii K, Kato H, Nishida E, Saito C, Morita A. Efficacy of excimer light therapy $(308 \mathrm{~nm})$ for palmoplantar pustulosis with the induction of circulating regulatory T cells. Exp Dermatol 2001; 20(9): 768-70.

10. Gao L, Li K, Li F et al. Polymorphisms in the FOXP3 gene in Han Chinese psoriasis patients. J Dermatol Sci 2010; 57(1): 51-6.

11. Gondek DC, Lu LF, Quezada SA, Sakaguchi S, Noelle RJ. Cutting Edge: Contact-mediated suppression by $\mathrm{CD} 4{ }^{+} \mathrm{CD} 25^{+}$regulatory cells involves a granzyme B-dependent, perforin-independent mechanism. J Immunol 2005; 174(4): 1783-6.

12. Goodfield M, Kownacki S, Berth-Jones J. Double-blind, randomised, multicentre, paralel group study comparing $1 \%$ coal tar preparation with $5 \%$ coal tar preparation in psoriasis. J Dermatol Treat 2004; 15(1): 14-22.

13. Grossman WJ, Verbsky JW, Barchet W, Collona M, Atkinson JP, Ley TJ. Human $\mathrm{T}$ regulatory cells can use the perforin pathway to cause autologous target cell death. Immunity 2004; 21(4): 589-601.
14. Hirahara K, Liu L, Clark RA, Yamanaka K, Fuhlbrigge RC, Kupper TS. The Majority of Human Peripheral Blood CD4+CD25highFoxp3+ Regulatory T Cells Bear Functional Skin-Homing Receptors. J Immunol 2006; 177(7): 4488-94.

15. Hofmeister R, Khaled AR, Benbernou N, Rajnavolgyi E, Muegge K, Durum SK. Interleukin-7: physiological roles and mechanisms of action. Cytokine Growth Factor Rev 1999; 10(1): 41-60.

16. Huber S, Schramm C, Lehr HA et al. Cutting Edge: TGF- $\beta$ signaling is required for the in vivo expansion and immunosuppressive capacity of regulatory $\mathrm{CD} 4{ }^{+} \mathrm{CD} 25^{+}$ T cells. J Immunol 2004; 173(11): 6526-31.

17. Jonuleit H, Schmitt E, Stassen M, Tuettenberg A, Knop J, Enk AH. Identification and functional characterization of human $\mathrm{CD} 4{ }^{+} \mathrm{CD} 25^{+} \mathrm{T}$ cells with regulatory properties isolated from peripheral blood. J Exp Med 2001; 193(11): 1285-94.

18. Kimball AB, Kupper TS. Future perspectives/quo vadis psoriasis treatment? Immunology, pharmacogenomics, and epidemiology. Clin Dermatol 2008; 26(5): 554-61.

19. Kortuem KR, Davis MD, Witman PM et al. Results of Goeckerman treatment for psoriasis in children: a 21-year retrospective review. Pediatr Dermatol 2010; 27: 518-24.

20. Kursar M, Bonhagen K, Fensterle J et al. Regulatory CD4+CD25+ T Cells Restrict Memory CD8+ T Cell Responses. J Exp Med 2002; 196(12): 1585-92.

21. Lan RY, Mackay JR, Gershwin ME. Regulatory T cells in the prevention of mucosal inflammatory diseases: Patrolling the bordur. J Autoimmun 2007; 29(4): 272-80.

22. Lebwohl M, Ali S. Treatment of psoriasis. Part 1. Topical therapy and phototherapy. J Am Acad Dermatol 2001; 45(4): 487-98.

23. Li Y-YY, Zollner TM, Schön MP. Targeting leukocyte recruitment in the treatment of psoriasis. Clin Dermatol 2008; 26(5): 527-38.

24. Liu W, Putnam AL, Xu-Yu Z et al. CD127 expression inversely correlates with FoxP3 and suppressive function of human CD4+ T reg cells. J Exp Med 2006; 203(7): 1701-11.

25. Ochs HD, Oukka M, Torgerson TR. TH17 cells and regulatory T cells in primary immunodeficiency diseases. J Allergy Clin Immunol 2009; 123(5): 977-83.

26. Piccirillo CA, Shevach EM. Control of CD $8+T$ cell activation by CD4+CD25+ immunoregulatory cells. J Immunol 2001; 167(3): 1137-40.

27. Quaglino P, Bergallo M, Ponti R., et al. Th1, Th2, Th17 and regulatory T cell pattern in psoriatic patients: modulation of cytokines and gene targets induced by etanercept treatment and correlation with clinical response. Dermatology 2011; 223(1): 57-67.

28. Roelofzen JH, Aben KK, van der Valk PG et al. Coal tar in dermatology. J Dermatolog Treat 2007; 18: 329-34.

29. Saito C, Maeda A, Morita A. Bath-PUVA therapy induces circulating regulatory T cells in patients with psoriasis. J Dermatol Sci 2009; 53(3): 231-3.

30. Sakaguchi S. Naturally arising Foxp3-expressing CD25+CD4+ regulatory T cells in immunological tolerance to self and non-self. Nat Immunol 2005; 6(4): 345-52.

31. Sugiyama H, Gyulai R, Toichi E et al. Dysfunctional blood and target tissue CD4+CD25high regulatory $\mathrm{T}$ cells in psoriasis: mechanism underlying unrestrained pathogenic effector T cell proliferation. J Immunol 2005; 174(1): 164-73.

32. Taams LS, Van Amelsfort JM, Tiemessen MM et al. Modulation of monocyte/ macrophage function by human CD4+CD25+ regulatory T cells. Hum Immunol 2005; 66(3): 222-30.

33. Thornton AM, Shevach EM. CD4+CD25+ immunoregulatory T cells suppress polyclonal $\mathrm{T}$ cell activation in vitro by inhibiting interleukin 2 production. J Exp Med 1998; 188(2): 287-96.

34. Trzonkowski P, Szmit E, Mysliwska J, Dobyszuk A, Myśliwski A. CD4 ${ }^{+} \mathrm{CD} 25^{+}$ $\mathrm{T}$ regulatory cells inhibit cytotoxic activity of $\mathrm{T} \mathrm{CD} 8^{+}$and NK lymphocytes in the direct cell-to-cell interaction. Clin Immunol 2004; 112(3): 258-67.

35. Venken K, Hellings N, Broekmans T, Hensen K, Rummens JL, Stinissen P. Natural naive $\mathrm{CD} 4+\mathrm{CD} 25+\mathrm{CD} 127$ low regulatory $\mathrm{T}$ cell (Treg) development and function are disturbed in multiple sclerosis patients: recovery of memory Treg homeostasis during disease progression. J Immunol 2008; 180(9): 6411-20.

36. Verhagen J, Akdis M, Traidl-Hoffmann C et al. Absence of T-regulatory cell expression and function in atopic dermatitis skin. J Allergy Clin Immunol 2006; 117(1): 176-83.

37. Vojdani A, Erde J. Regulatory T cells, a potent immunoregulatory target for CAM researchers: modulating tumor immunity, autoimmunity and alloreactive immunity (III). Evid Based Complement Alternat Med 2006; 3(3): 309-16.

38. Zhang L, Yang XQ, Cheng J, Hui RS, Gao TW. Increased Th17 cells are accompanied by FoxP3(+) Treg cell accumulation and correlated with psoriasis disease severity. Clin Immunol 2010; 135(1): 108-17.

39. Zheng SG, Wang J, Wang P, Gray JD, Horwitz DA. IL-2 Is Essential for TGF- $\beta$ to Convert Naive CD4+CD25+ Cells to CD25+Foxp3+ Regulatory T Cells and for Expansion of These Cells. J Immunol 2007; 178(4): 2018-27.

Received: $16 / 11 / 2011$

Accepted in revised form: 01/06/2012

\section{Corresponding author:}

Kateřina Kondělková, MSc., Charles University in Prague, University Hospital Hradec Králové, Department of Clinical Immunology and Allergology, Sokolská 581, 50005 Hradec Králové, Czech Republic; e-mail: katerina.kondelkova@seznam.cz 